\title{
Digital financial inclusion: next frontiers-challenges and opportunities
}

\author{
Chandra Mohan Malladi $^{1}$ (i) $\cdot$ Rupesh K. Soni $^{1} \cdot$ Sanjay Srinivasan $^{1}$
}

Received: 1 June 2021/Accepted: 4 July 2021/Published online: 18 August 2021

(C) CSI Publications 2021

\begin{abstract}
India's Financial Inclusion journey has been phenomenal in the last decade and expressly promoted by the Government of India through their Digital India Movement \& Pradhan Mantri Jan Dhan Yojana. Reduction of poverty and addressing the challenges of ensuring sustainable income could become a key factor to achieve an inclusive society. Information and Communication Technology are providing access to unbanked population progressively and helping to bring them into the banking segment. Digital Technologies are driving usage and making a positive impact on livelihood of citizens. In this paper we are discussing on what is achieved in Financial Inclusion so far and what next and how do we leverage and harness digital technologies to achieve an inclusive society. This paper enlists various challenges that continue to prevail in achieving an inclusive society. We have put forth recommendations on addressing the key challenges and qualified the importance of collaboration and transparency between all the key stakeholders to achieve an inclusive ecosystem.
\end{abstract}

Keywords Financial Inclusion - Information and Communication Technology $\cdot$ Social Inclusion $\cdot$ Health Inclusion · Sustainable Growth

Chandra Mohan Malladi

cm.malladi@tcs.com

Rupesh K. Soni

rupesh.soni@tcs.com

Sanjay Srinivasan

sanjay.srinivasan@tcs.com

1 Enterprise Business Platforms, Tata Consultancy Services, Mumbai, India

\begin{tabular}{|c|c|}
\hline \multicolumn{2}{|l|}{ Abbreviations } \\
\hline PoS & Point of Sale \\
\hline MSME & $\begin{array}{l}\text { Micro, Small and Medium } \\
\text { Enterprises }\end{array}$ \\
\hline RBI & Reserve Bank of India \\
\hline PM JDY & $\begin{array}{l}\text { Pradhan Mantri Jan Dhan } \\
\text { Yojana }\end{array}$ \\
\hline PMJJBY & $\begin{array}{l}\text { Under PM Jeevan Jyoti Bima } \\
\text { Yojana }\end{array}$ \\
\hline APY & Atal Pension Yojana \\
\hline PMSBY & $\begin{array}{l}\text { Pradhan Mantri Suraksha } \\
\text { Bima Yojana }\end{array}$ \\
\hline APBS & $\begin{array}{l}\text { Aadhaar Payments Bridge } \\
\text { System }\end{array}$ \\
\hline CBS & Core banking system \\
\hline PM KISAN & $\begin{array}{l}\text { PM Kisan Samman Nidhi } \\
\text { Yojana }\end{array}$ \\
\hline PM SVANidhi & $\begin{array}{l}\text { PM Street Vendors' } \\
\text { Atmanirbhar Nidhi }\end{array}$ \\
\hline $\begin{array}{l}\text { Micro Units Development } \\
\text { and Refinance Agency }\end{array}$ & Pradhan Mantri MUDRA \\
\hline PM MUDRA & Yojana \\
\hline BHIM & Bharat Interface for Money \\
\hline UPI & Unified Payments Interface \\
\hline $\mathrm{NACH}$ & $\begin{array}{l}\text { National Automated } \\
\text { Clearing House }\end{array}$ \\
\hline BC Network & $\begin{array}{l}\text { Business correspondent } \\
\text { network }\end{array}$ \\
\hline DBT & Direct benefit transfer \\
\hline AEPS & $\begin{array}{l}\text { Aadhaar enabled payments } \\
\text { system }\end{array}$ \\
\hline CTS & Cheque truncation system \\
\hline NPCI & $\begin{array}{l}\text { National Payments } \\
\text { Corporation of India }\end{array}$ \\
\hline
\end{tabular}




\begin{tabular}{|c|c|}
\hline ICT & $\begin{array}{l}\text { Information and } \\
\text { Communication Technology }\end{array}$ \\
\hline IPPB & Indian Post Payment Bank \\
\hline PM JAY & PM Jan Arogya Yojana \\
\hline RWBCIS & $\begin{array}{l}\text { Restructured Weather Based } \\
\text { Crop Insurance Scheme }\end{array}$ \\
\hline NFC & Near Field Communication \\
\hline NBFC & $\begin{array}{l}\text { Non-Banking Financial } \\
\text { Company }\end{array}$ \\
\hline
\end{tabular}

\section{Hypotheses Development}

How do we enhance the process of Digital Financial Inclusion? How can Information and Communication Technology help in providing the citizens with a sustainable livelihood and inclusive growth? How can we safeguard the people who are included in the FI Framework and guarantee that they will not be excluded again?

To achieve a financially inclusive society that is sustainable and promotes inclusive growth for all, we need to provide the citizens of the country with access to education, basic financial services, affordable healthcare \& suitable way for upskilling and improving their talent. They should be brought inside the legal framework where they can sustain and thrive.

The high amount of disparity and digital divide between Urban \& Rural areas in India must be eliminated and people must be educated financially and included socially. There must be a cohesive ecosystem where Financial, Social \& Health Inclusion that can work in tandem to accomplish a sustainable inclusive society. India's digital payment and rural infrastructure must be improved to ensure zero disruption and continual access to telecom networks. Access to line of credit must be provided with adequate last mile services to ensure service delivery.

\section{Deployment Approach and Methodology}

This research study used quantitative and qualitative data from various official sources such as websites of Reserve Bank of India, Niti Aayog, Direct Benefit Transfer, PM Jan Dhan Yojana and other information published officially by the Govt. of India and Ministry of Finance. The data points and facts visibly showcase the impact of Financial Inclusion so far in India and helps us understand the gaps that must be filled to improve growth and ensure sustainability.

Comprehensive secondary research from published journal articles and expert committee opinions were considered to understand Digital Financial Inclusion initiatives and details of the best practices followed in various geographies. By leveraging this information, we have identified the key problems preventing us to realize an inclusive society and we have provided with qualified recommendations to tackle this.

Inclusive society is well-defined in terms of Financial Inclusion, Social Inclusion \& Health Inclusion. Consistent with this approach, we define our key dependent variables 'finance'-as the access to a line of credit, availability and usage of basic financial services, 'social'-access to education and literacy, improvement of skills, \& 'health'Personal \& Societal Wellness. From this, we can understand that we are deploying a self-reporting measure to evaluate our research findings and we have substantiated our recommendations with real world examples from other studies conducted in similar functions. Prior research also acknowledges the subjectivity of these self-reported measures of FI [24].

\section{Introduction}

Financial Inclusion (FI) means delivering basic financial services to the marginalised and excluded members of society. It is the process in which we ensure adequate line of credit accessible by the weaker section of the society at a reasonable cost. Financial inclusion helps in developing a culture of savings among semi urban and rural population by bringing low income groups within the formal framework of banking and insurance sector which is significant for national economic development. It came into prominence around 2008 when it became clear to the government that it needs to be the key driver for economic growth of the country. Vision for Financial Inclusion in India is to induce inclusive financial growth by including the unbanked and unsupported individuals and MSMEs by formal financial institutions by providing them convenient access to basic financial products including bank accounts, remittances, bill payments, government supported insurance, pension products and formal credit at reasonable costs. There has been a growing evidence on how financial inclusion has a multiplier effect in boosting overall economic output, reducing poverty and income inequality at the national level.

With the advent of "Digital India Movement" and telecom penetration to deep rural areas, sincere efforts are made to bring widespread formal banking channels and innovative financial technology together to create a viable and vibrant ecosystem to drive accessibility of formal financial products to unbanked and deprived segments of Indian society. We at TCS, started this journey very early for some of our partner banks, with the services related to opening of no-frills accounts, delivering smart cards 
containing balance and biometric information to registered on the card. There was no active network connectivity during initial stages of FI. Last mile agents used to visit the bank, withdraw money \& beneficiary list, go to each beneficiary, authenticate with biometrics, and deliver the services. Post which, they go back to the bank to reconcile. Out of 650,000 villages in India, around 150,000 was identified by the govt. initially to service through $\mathrm{BC}$ Model [15].

Fast-forward now, there is far more online connectivity in the remotest areas, smart card is replaced by real time Aadhaar based authentication, beneficiary enrolment \& transactions can be done in real-time in field. Last mile channels like micro ATMs, Kiosks, PoS machines, Tablets, Mobile Phones are utilised for service delivery. Basic requirement of UPI based FI transaction is that the beneficiary account should be opened through PM JDY scheme and it is linked to the customer's mobile number. Banks started channelling UPI based transactions on opened bank accounts. As of 2019, little over $470 \mathrm{Mn}$ ( $34.47 \%$ ) is urban population of India. However, more than $65 \%$ are in semi urban and rural areas where access to digital services is lesser than major cities [13].

There is a great need for inclusive growth. By leveraging digital technologies, this is a great opportunity for Govts. and market leaders to improve digital penetration, ease of use of digital products, contextualised and personalised offerings to citizens increase availability, drive down costs, enhance security and trust. There is a need for sustainable cooperation between govts., businesses and unbanked population [15].

National leadership and policy making institutions like RBI and Niti Aayog have brought in some strong initiatives for inclusive growth which culminated in National Mission for Financial Inclusion namely Pradhan Mantri Jan Dhan Yojana PM JDY leveraging banking network and technology innovations. It enabled access to financial services and coverage of banking to excluded population.

Till date over 344.3 Mn plus new accounts have been opened and a bunch of social and financial security products are offered to the account holders like entrepreneurial credit, financial advice, mortgage, loans and insurance, overdraft of ₹10,000, Accidental Death cum Disability Insurance (PMSBY), Term Life Cover under PMJJBY, Old Age Pension (APY scheme), PM Kisan, Educational Scholarships to students etc. [6].

With over $95 \%$ of Indian population having Unique Identification through Aadhaar, India achieved $80 \%$ of adult population having bank account by $2017.77 \%$ Indian Women have bank accounts. In the outbreak of Covid-19 pandemic, this back bone of bank account has been instrumental to provide help of ₹500 per month for 3 months to over $200 \mathrm{Mn}$ woman beneficiaries, transfer of
₹6000/- in 3 instalments per year (currently citizens are receiving their 8th instalment) of PM Kisan Samman Nidhi Yojana to farmers through direct benefit transfer schemes [10]. Under PM JDY, 423.7 Mn total no of Beneficiaries of which 279.5 Mn Semi Urban/ Rural Beneficiaries [24]. Rapid digital penetration along with enhancing the financial literacy of people has started. We are moving from assisted to self-service model for multiple services.

For almost all the public and private sector banks, TCS has provided its Financial Inclusion Solution Suite enabling end to end integration with their core banking systems (CBS) through its Branchless Banking Solution. With a wide range of services catalogue, TCS is delivering last mil services to over 150 + thousand locations. TCS has been the technology service provider (TSP) to DBT for various stake holders in which we are running a Heterogenous Technology System for money transfer. TCS is co-ordinating with multiple stakeholders in the DBT value chain such as Central \& State Govts., banks \& financial institutions in the country, RBI. DBT has proven to be critical in arresting leakage of govt. funds ( ₹1700 $\mathrm{Bn}$ ), eliminate involvement of middlemen in transactions, has capacity to cover a variety of areas, increase the number of beneficiaries ( $\sim 770 \mathrm{Mn}$ ) and transactions and lower the distribution cost per transaction (Over $6 \mathrm{Mn}$ Trnxs/day) [11].

Multiple technological solutions such as FI Platform, Beneficiary Registration Application, TCS BaNCS Enterprise Payments Hub, APBS (Aadhaar Payment Bridge System) Adaptor, TCS BaNCS CBS, Aadhaar Data Vault Solution were implemented by TCS and leveraged for endend service delivery. RBI has played the guiding role which helped banks in achieving various objectives such as the introduction of MICR based cheque processing, Implementation of the electronic payment system such as RTGS (Real Time Gross Settlement), Electronic Clearing Service (ECS), Electronic Funds Transfer (NEFT), Cheque Truncation System (CTS), Mobile Banking System etc. [8].

Further to that, under the Digital India Movement, various digital payment methods-UPI, BBPS, IMPS, NETC, AePS, etc. were launched by NPCI, in coordination with RBI, some of which was run by TCS on behalf of RBI \& NPCI. RBI's working group reviewed the BC Model and suggested that BC agents or BF agents (Business Facilitator) can deliver last mile services in semi urban \& rural areas. Individuals working as PCO Operators, Retired Teachers, Petrol Pump Owners, Grocery, Chemist \& Fir Price Shop owners, NGOs, MFIs, SHGs linked to banked were authorised to act as last mile agents and provided a commission based on amount of services rendered [9].

There is a huge market for several financial institutions $\&$ other ecosystem players in the bottom of the pyramid by creating right products \& services and ensures it reaches 
the intended customer [15]. TCS has been chosen as primary service provider for kiosk banking solution for many of the Customer Service points established by various Public Sector Banks (PSBs).

\section{Current Challenges and Observations}

1. People included in the Financial inclusive ecosystem end up getting excluded and are not able to sustain within the framework due to various reasons general or health related causes [1].

2. There is a clear demarcation of digital divide among - some are tech savvy people and delivering the services and making them understand is not difficult, where as some in semi-urban and majority of people in rural areas find difficult to understand and utilise technology efficiently [16].

3. Lack of financial literacy and awareness on financial cybercrimes has resulted in general mistrust among rural population which leads to reduced digital penetration [27].

4. There is a burden on running sustainable last mile delivery model, particularly in rural areas \& last mile level service delivery. Multiple Govt. \& Business agencies are trying to reach the same location for various reasons related to FI, Social or Healthcare inclusion and these are disjoint efforts and driving higher costs.

5. Different data elements available with govt. such as healthcare schemes data, social inclusion data, COVID data, vaccination data, etc. are not leveraged to full extent as there is clear lack of coherence between these data elements.

6. Last mile technological systems and artefacts are vulnerable to exposure and exploitations. It is loosely handled by $\mathrm{BC}$ or $\mathrm{BF}$ agents as adequate security measures to control it are not put in place. This has resulted in lot of frauds happening on the ground. About 22\% BC agents faced fraud in 2017, a noteworthy increase from $2 \%$ in 2015 [17]. Business model of Last mile \& BC Agent network must be looked at again from privacy security \& safety angle.

7. Data Privacy is still a major concern as a lot of captured data is easily available to various stakeholders as PII norms are not completely followed. KYC Data \& mobile numbers are available everywhere.

a. Biometric data is captured duplicitously by some BC Agents in clay who will replicate it later for fraudulent reasons. b. Another way is when they give a manual receipt instead of computerised one during transactions.

8. SMS messages for transactions in an account are not reaching the customer due to lack of mobile device (More than $310 \mathrm{Mn}$ people still do not possess a basic feature phone or a smart phone) or financial institutions are not sending these messages for low value transactions. This has led to increased dependency on local agents.

9. Access to credit is still a concern as small time lenders charging high rate of interest are prevalent in rural areas. Govt. schemes have not penetrated fully and need more rural outreach to enhance credit access [15]. Lack of avenues for digital lending and online loans from credible financial institutions is missing.

10. Recommendations for individuals based on their requirement is not provided and leveraging the personalised data of the person, by performing analytics using AI \& ML, banks can offer loans, insurance and other services based on analytics \& credit score [15].

\section{National Strategy for Financial Inclusion}

In the year 2020, RBI came up with national strategy for Financial Inclusion with focus on creating an outreach of financial services outlets to provide banking access to every household within $5 \mathrm{KM}$ radius. All eligible adults must have access to basic financial services such as Bank Account, line of credit, both life and other insurance, pension scheme and suitable investment product. Now, the next paradigm for financial inclusion program (2020-2024) is focused addressing inherent behavioural and practical aspects [22].

1. A strong financial transaction grievance redressal system to address concerns of arguably less technology savvy citizens.

2. Increasing digital penetration as still the smartphone usage for financial transactions are limited to urban and semi urban population predominantly.

3. Bank account opening for the remaining population of the country as still the PMJDY penetration is about $80 \%$ of the population.

4. Ensuring the privacy of data and information of citizens and prevention of fraudulent transactions and demographic data.

5. Easy and affordable digital payment options to suit the needs of small businesses and unstructured sector workers. 
6. Providing access to basic and most essential financial products such as transactional accounts, digital payments, basic term insurance, basic medical insurance, and pension options to the population specially in the agricultural and unorganized MSME sector workers.

Acc. to a World Bank report, globally achieving Universal Financial Access by 2020 [3] has been one of the key developmental agenda of the World Bank which aims to provide adults who currently aren't part of the formal financial system, with access to a transaction account to store money, send and receive payments to manage their financial lives. Our National Strategy is also aligned to these broad virtues suggested by World Bank. On key parameters, India is quite ahead and continuously progressing:

1. Leadership in India is having singular focus on technology enabled financial inclusion. It is evident through steps like DBT, PM Kisan, financial assistance to woman and poor during the recent Covid-19 pandemic etc.

2. Target based approach for specific sectors \& regions including "National Mission for Capacity Building" by bankers for MSME sector, Certified Credit Counsellor Scheme for MSME to join them with the formal Financial Channels and informed financial credit decisions.

3. Regulatory Framework in Banking to protect customers, promote fair business processes and prevent unhealthy practices by market players. Initiatives like exclusive "Financial Inclusion Fund" (with initial corpus Rs.2000 Crore), issuances of differentiated banking license-Small Finance Banks, Payments Banks etc., launch of BC Registry with Indian Banks Association (IBA) etc. are steps towards the same.

4. Market Development initiatives like Branch Authorization Guidelines (2017) etc. to ensure accurate targeting of the beneficiaries, de-duplication and reduction of fraud and leakage have been taken. Linking all financial assistance schemes to DBT is a strong footprint in this direction

5. Strengthening Payments Structure through digital retail payments systems like AEPS, NACH, UPI, CTS, IMPS etc. operated by NPCI are significant steps. Aadhaar linked direct benefit transfer has changed the scenario for public funds distribution in India.

6. Last mile delivery to bridge the gap for remote connectivity and doorstep financial services is key to success. ICT based solution like business correspondents/ facilitators and IPPB are landmark steps in this area, launch of UPI on features phones will be a big game changer also enabling ecosystem for NFC based touch less payments.
7. Financial Literacy and Awareness is a primary bottleneck in progressive financial inclusion in India. Launch of financial literacy program in 2013 helped in addressing this to some extent.

\section{Sustainability through Comprehensive Inclusion}

An inclusive society helps sustain socioeconomic development and understanding the correlation between Financial Inclusion, Social Inclusion \& Health inclusion helps sustainability. Having taken the right initiatives to ensure wider coverage of Financial Inclusion, it is now time to look at the rationalization of the inclusive society by leveraging iterative technology and other two key aspects -Social Inclusion (Education, Literacy, Skill), Health Inclusion (Personal \& Societal Wellness).

FI implemented in a standalone ecosystem may not be enough to achieve. FI must be complemented by Social and Health Inclusion through improving skillset, education, physical and mental well-being to ensure a sustained livelihood [12]. Current model has a major short-coming. If there is a functionality lapse in any single inclusion, someone may fall out of the inclusive ecosystem.

We need to ensure that whoever is excluded financially is brought into the fold again and has all the necessary tools to sustain within the ecosystem.

To handle this, we need to focus on increasing the digital penetration and continue the account opening process for all citizens. FI Ecosystem must aim to work in tandem with Healthcare Inclusion \& Education Inclusion ecosystem to ensure well-being of people and educate the citizens financially. The technological initiatives under 'JAM Trinity', that is, PM Jan Dhan Yojana, Aadhaar and increased Mobile Phone \& internet usage had led to $355 \mathrm{Mn}$ accounts opened in the last 5 years (Figs. 1, 2).

Technology should drive the recommendations to every individual to ensure social, health and fin. Inclusion. Cross Leveraging of existing and new citizen databases to provide strategic Analytics \& insights to the deciding authorities.

Blockchain could prove to be a gamechanger in enhancing the value chain securely without any duplications of efforts [23]. There following measures could be taken to improve the living standard of citizens using ICT technology to deliver last mile services [19]. They are,

1. Fix technological breakdowns and connectivity issues and ensure wider coverage in remote areas

2. Facilitate a hassle-free digital experience for new users

3. Enhance digital security standards to improve the confidence of citizens to make digital transactions 


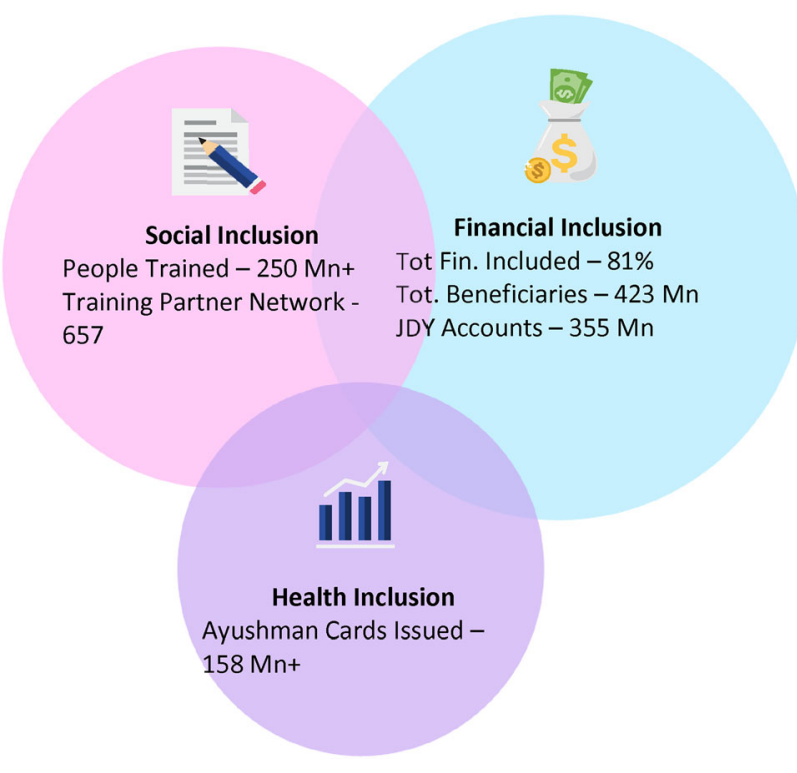

Fig. 1 Current State in India

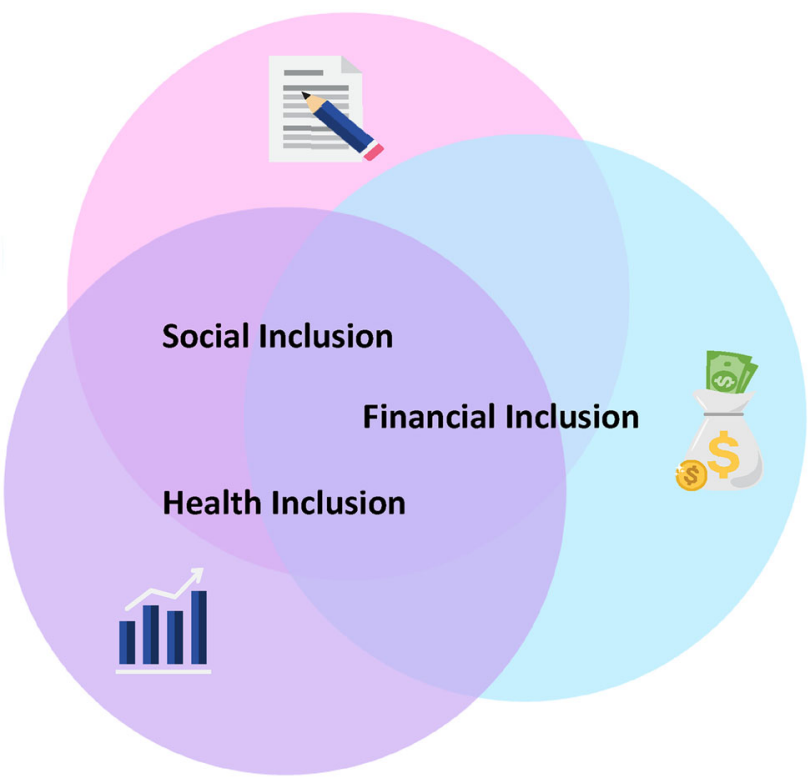

Fig. 2 Desired State in India

4. Finetuning limits on daily transactions and commissions on low value withdrawals \& deposits

5. Make changes to the minimum balance criteria in SB Accounts

6. Delivery services at BC points through Controlled devices for better safety and security for end users

People should be educated and learn to protect themselves against financial cybercrimes. Provide profile wise recommendations and better offers for people by leveraging Analytics, AI \& ML using the data gathered from available official databases. For ex., through COVID
Patient DB, recommendation for vaccination, availability of various health insurance schemes, access to medical loans could be provided. Building information sharing systems leveraging multiple public databases is crucial for success.

One such example may be leveraging the vaccination database to provide profile wise vaccination recommendations, information regarding availability of loan and credit lines, developing a 'fraud repository', and ensuring that online digital commerce platforms carry warnings to alert consumers to the risk of frauds etc. can play a game changer role in FI endeavours. RBI has guided banks to introduce a General-Purpose Credit Card (GCC) facility. It is revolving credit which entitles the card holder to make transactions of Rs 25,000 above the credit limit. This is completely based on customer's credit assessment and the limits are sanctioned without any security or collateral. Rate of Interest on revolving credit is deregulated. Under PM SVANidhi Scheme, micro lending amount of up to Rs 10,000 is provided to street vendors as working capital. Under PM MUDRA scheme, credit is provided to noncorporate, non-farm SMEs up to Rs 1 million. Microfinance institutions can help widen the coverage of reach by offering their services in remote areas using analytics \& basic credit risk assessment [20].

\section{Observations and Recommendations for accelerating Financial Inclusion}

Innovations in the field of technology \& communications strongly complements the FI ecosystem which results in inclusive socio-economic growth. This improves transparency and competitive efficiency, has the potential to reduce cost of service delivery and strengthens the backend administrative processes [21].

The objective of providing a basic bouquet of financial services can be achieved through designing and developing customized financial products by banks and ensuring efficient delivery of the same through leveraging of FinTech and BC networks [18]. Some of the constructive recommendations are following-

1. Combining Financial inclusion with health inclusion and Social Inclusion to make the it more inclusive for citizens in the lower strata of the society. PM SBY, PM JJBY, RWBCIS, Ayushman Bharat (PM JAY) must be promoted. Till date, 158 Million + Ayushman Cards issued which requires expedite efforts to reach the full population of eligible citizens.

2. By analysing the impact of COVID-19, we can leverage FI and drive vaccination programs and other welfare schemes such as access to Medical Insurance 
\& Loans for the needy. Comprehensive coverage of Health \& Wellness through various initiatives to drive Health \& Social Inclusion to achieve a sustainable growth [7].

3. Crucial aspect of FI is Financial Literacy [27]. Promote Financial Literacy and educate people on features such as Phone Banking, UPI \& NFC enabled feature phones can be made available at low cost, enhance touchless payment (NFC \& QR) framework. Common features such as Bill Payments, Ticket Booking are already interoperable through Bharat QR.

4. Strengthening the payment infrastructure to promote a level playing field for (NBFCs) and banks. Digitizing registration and compliance processes and diversifying credit sources to enable growth opportunities for MSMEs is an essential step for comprehensive inclusion [2].

5. Enabling agricultural NBFCs to access low-cost capital and deploy a 'physical' (physical+digital) model suggested by Niti Aayog for achieving better longterm digital outcomes is a crucial step. Digitizing land records will also provide a major boost to the sector.

6. Tech should aim to reduce cost per transaction and continue to drive the recommendation to every individual to ensure, social, health and financial inclusion and ensure that the money has been reaching the last mile beneficiary at low costs [26].

7. By combining digital education tools \& digital financial tools, and slight changes to tax regulations, underbanked \& unbanked people can break the chain of poverty and sustain successfully in a cash lite economy [5].

8. Geospatial technology could be used to analyse the population density of target service areas so that there is a clear understanding of required amount of work force for a particular area and can also be used to identify gaps in current services [25].

\section{Summary of Key Problems we identified}

Summary of problems identified \& possible solutions in brief is displayed below in Table 1 .

In conclusion, we can say that a technological, multifaceted \& dynamic approach centred around enhancing financial literacy, social \& education inclusion, improved cybersecurity \& stricter laws, enhanced digital infrastructure is mandatory for wider coverage of next wave of financial inclusion in the country.

Table 1 Summary of findings with proposed solution

\begin{tabular}{|c|c|c|}
\hline $\begin{array}{l}\text { S. } \\
\text { No }\end{array}$ & Identified issue & Common solution in brief \\
\hline 1 & $\begin{array}{l}\text { Exclusion from Financial, Social or } \\
\text { Healthcare inclusion framework }\end{array}$ & $\begin{array}{l}\text { Acc. to [28], by promoting financial literacy, there was visible reduction in Financial } \\
\text { exclusion once the people are educated on financial services \& are aware the digital } \\
\text { products available for usage }\end{array}$ \\
\hline 2 & $\begin{array}{l}\text { Lack of satisfactory last mile connectivity \& } \\
\text { infrastructure }\end{array}$ & $\begin{array}{l}\text { FI regulators to work with telecom operators to establish stable network connectivity in } \\
\text { rural areas }\end{array}$ \\
\hline 3 & Divergent last mile infrastructure & $\begin{array}{l}\text { Multiple stakeholders trying to reach the same location for various purposes should be } \\
\text { reduced and efforts should be taken jointly to share resources, if required [1] }\end{array}$ \\
\hline 4 & $\begin{array}{l}\text { Incoherent Data in Govt./Public information } \\
\text { data base }\end{array}$ & $\begin{array}{l}\text { Data available in Govt. and public information databases must be collected \& shared in } \\
\text { using distributed ledger technology to prevent wastage of resources \& help identify } \\
\text { problem areas more easily [14] }\end{array}$ \\
\hline 5 & Lack of data privacy & $\begin{array}{l}\text { Regulators must strictly enforce and give directions to all stakeholders instructing that data } \\
\text { consent from customer should be received before sharing, all data must be protected with } \\
\text { encryption \& stakeholders must follow all the guidelines }\end{array}$ \\
\hline 6 & No stable source of income for individuals & Individuals must be provided skills enhancement training or basic education \\
\hline 7 & Lack of access to Line of Credit & $\begin{array}{l}\text { People should be educated on existing \& new govt. schemes providing low interest lending } \\
\& \text { regulators must ensure related services are delivered successfully [4] }\end{array}$ \\
\hline 8 & $\begin{array}{l}\text { No profile based personalised } \\
\text { recommendation for products \& services }\end{array}$ & $\begin{array}{l}\text { By leveraging data available in public information \& govt. databases, personalised } \\
\text { recommendation must be made by deriving strategic insights from it using AI/ML }\end{array}$ \\
\hline 9 & $\begin{array}{l}\text { Affordability of basic feature phone or smart } \\
\text { phone }\end{array}$ & $\begin{array}{l}\text { Govt. can tie up with private mobile manufacturers to offer feature or smart phones at a } \\
\text { subsidized price }\end{array}$ \\
\hline 10 & $\begin{array}{l}\text { Increase in financial cybercrime \& identity } \\
\text { thefts }\end{array}$ & $\begin{array}{l}\text { Citizens should be made financially aware of the technological regulations put in place to } \\
\text { protect them and must be taught about the safe practices in digital payments during } \\
\text { village meetings \& gatherings }\end{array}$ \\
\hline
\end{tabular}


Funding None.

Data availability All the data used in this paper for research purposes are properly cited with references to Source.

\section{Declarations}

\section{Conflict of interest None.}

Consent to participate Consented.

Consent for publication Consented.

\section{References}

1. Albert P-U, Sílvia B, Dolors C, Dolores Á-J, Luïsa OG, Àngels O, Joan-Pau M (2020) Evidences supporting the inclusion of immigrants in the universal healthcare coverag. Eur J Public Health. https://doi.org/10.1093/eurpub/ckaa020

2. Babajide AA, Oluwaseye EO, Lawal AI, Isibor AA (2020) Financial technology, financial inclusion and msmes financing in the south: West of Nigeria. Academy of Entrepreneurship JOURNAL. 26

3. Bank W (2018) UFA2020 Overview: Universal Financial Access by 2020 . Retrieved from World Bank: https://www.worldbank. org/en/topic/financialinclusion/brief/achieving-universal-finan cial-access-by-2020

4. Birgitta DS, Ghozali M, David K, Rachmad KS (2020) The effect of financial inclusion and financial technology on effectiveness of the indonesian monetary policy. Bus Theor Pract. 21-24

5. Chu AB (2018). Chapter 6: mobile technology and financial inclusion. handbook of blockchain, digital finance, and inclusion. Volume 1

6. Committee R (2008) Rangarajan committee report on financial inclusion. IMaCS Research, RBI

7. Cornelius CA, Qusay HM, Mikael E (2019) Blockchain technology in healthcare: a systematic review. Healthcare. https://doi. org/10.3390/healthcare7020056

8. Gupta SK (2011) Financial Inclusion: IT as enabler. Reserve Bank of India Occasional Papers

9. IBEF (2019) Technology application for financial inclusion. India Brand Equity Foundation

10. India D (2021) PM Kisan Samman Nidhi 8th installment: Get Rs 2,000. Retrieved from DNAIndia: https://www.dnaindia.com/per sonal-finance/report-pm-kisan-samman-nidhi-8th-installmentget-rs-2000-by-this-date-check-your-name-on-beneficiary-list2888141

11. India GO (2021) Direct benefit transfer. Retrieved from DBT Bharat: https://dbtbharat.gov.in
12. Isukul A, Tantua B (2021) Financial inclusion in developing countries: applying financial technology as a Panacea. South Asian J Social Stud Econ. https://doi.org/10.9734/sajsse/2021/ v9i230237

13. JDY P (2021) PM Jan Dhan Yojana. Retrieved from https:// pmjdy.gov.in/

14. Jesse LM, Blake M (2017) Banking on distributed ledger technology: can it help banks address financial inclusion? Economic review. 3rd Quarter

15. Malladi CM (2020) Toward financial inclusion: executive viewpoint. MIT Sloan Management Review, India

16. Marco J (2018) The struggle for digital inclusion: phones, healthcare, and marginalisation in rural India. World Development, p 104

17. Mishra A, Komal G (2018) Microsave Report. Retrieved from Live Mint: https://www.livemint.com/Industry/4jL1r9XnS43Bb wdEOZEVLO/Over-20-of-business-correspondents-faced-fraudin-2017-Mic.html

18. Murthy G, Fernandez-Vidal M, Faz X, Barreto R (2019) Fintechs and financial inclusion: looking past the hype and exploring their potential. Consultative Group to Assist the Poor (CGAP)

19. Nirosha HW, Ahmed IH, Riadh M, Stuart M (2021) Information communication technology and financial inclusion of innovative entrepreneurs. Technological Forecasting and Social Change

20. Noronha M, Kumar VR (2019) Technology: a tool for achieving inclusive and sustainable growth through financial inclusion. CLEAR Int J Res Commerce Manag 10(2): 1

21. Ozili PK (2020) Financial inclusion research around the world: a review. Forum for Social Economics

22. RBI (2018) National strategy for financial inclusion 2019-2024. Reserve Bank of India: Executive Committee, India

23. Schuetz S, Venkatesh V (2020) Blockchain, adoption, and financial inclusion in India: research opportunities. Int J Inf Manag. https://doi.org/10.1016/j.ijinfomgt.2019.04.009

24. Sridhar N (2021) Jan Dhan accounts surge to $42 \mathrm{cr}$ with total balance at ₹1.4-lakh cr. Retrieved from The Hindu: https://www. thehindubusinessline.com/economy/jan-dhan-accounts-surge-to42-crwith-total-balance-at-14-lakh-cr/article34100792.ece

25. Ul Haq I, Gradstein HL (2020) Leveraging geospatial technology for financial inclusion: financial inclusion support framework. Open Knowledge Repository

26. Vrajlal S (2018) Chapter 14: financial inclusion, digital currency, and mobile technology. In: Handbook of blockchain, digital finance, and inclusion. p 27

27. Warhamni, Rahmi N (2021) Financial technology determination in terms of financial inclusion and financial literacy. In: Conference on economic and business innovation (CEBI), 1

28. Yan S, James H, Wenxiu H (2019) Using digital technology to improve financial inclusion in China. Appl Econ Lett. https://doi. org/10.1080/13504851.2019.1606401 